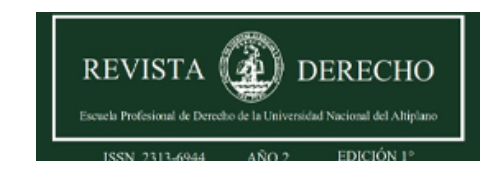

Revista de Derecho

ISSN: 2313-6944

ISSN: 2707-9651

revistaderecho@unap.edu.pe

Universidad Nacional del Altiplano

Perú

\title{
Palabras de finalización de gestión del Decano Boris Espezúa Salmón
}

Espezúa Salmón, Boris Gilmar

Palabras de finalización de gestión del Decano Boris Espezúa Salmón

Revista de Derecho, vol. 6, núm. 1, 2021

Universidad Nacional del Altiplano, Perú

Disponible en: https://www.redalyc.org/articulo.oa?id=671870928001

DOl: https://doi.org/10.47712/rd.2021.v6i1.145

\section{(c) (1)}

Esta obra está bajo una Licencia Creative Commons Atribución 4.0 Internacional. 
Editorial

\title{
Palabras de finalización de gestión del Decano Boris Espezúa Salmón
}

\author{
Final words from Dean Boris Espezúa Salmón \\ Espezúa Salmón, Boris Gilmar \\ Universidad Nacional del Altiplano de Puno, Perú \\ bgespezua@unap.edu.pe \\ iD https://orcid.org/0000-0002-1204-5404 \\ SC https://www.scopus.com/authid/detail.uri? \\ authorId $=57219743354$
}
DOI: https://doi.org/10.47712/rd.2021.v6i1.145
Redalyc: https://www.redalyc.org/articulo.oa? $\mathrm{id}=671870928001$

Recepción: 30 Julio 2021

Aprobación: 30 Julio 2021

Publicación: 30 Julio 2021

\section{RESUMEN:}

Doy cuenta de 04 años de haber estado al frente de la Decanatura de la Facultad de Ciencias Jurídicas y Políticas de la UNAPUNO. De manera general destacaré lo más relevante de lo que pudimos realizar en la presente gestión

Palabras Clave: decano, gestión.

\section{Abstract:}

I give an account of 04 years of having been in charge of the Dean of the Faculty of Legal and Political Sciences of UNA-PUNO. In general, I will highlight the most relevant of what we were able to do in this administration.

KEYWORDS: dean, management.

\section{SEÑORES CONSEJEROS, COLEGAS DOCENTES Y ESTUDIANTES:}

Doy cuenta de 04 años de haber estado al frente de la Decanatura de la Facultad de Ciencias Jurídicas y Políticas de la UNA-PUNO. De manera general destacaré lo más relevante de lo que pudimos realizar en la presente gestión:

1.- Asumí el cargo en agosto del 2017 y en aquél año, ya se encontraba trabajando el Comité de Calidad, que ha continuado como hasta la fecha conduciendo las actividades de lo que sería la segunda acreditación que se tiene pendiente aprobar. Es necesario destacar la labor Dr. Juan Casazola, y de todos los colegas que han apoyado y lo siguen haciendo para conseguir éste propósito fundamental para el futuro de nuestra Facultad.

2.- En el año 2018, se trabajó en el diseño de la nueva currícula de estudios que no se llegó a implementar, así mismo también se hizo funcionar el ascensor de la Facultad, y nos permitimos dotar con una compra extraordinaria de una cantidad considerable de libros para nuestra Biblioteca, salió la revista de nuestra Facultad, también se realizó algunos eventos académicos. En dicho año además se establecieron las oficinas de Tutoría y de Responsabilidad social.

Afines de dicho año, se celebró con el Poder Judicial, el acuerdo de realizar las publicaciones de dos tomos de Historia y Derecho, para que se pueda colaborar con artículos de Magistrados y Docentes, a propósito del Bicentenario de la República, hecho que se ha cumplido tanto en el año 2019 y 2020. Se ha mejorado la infraestructura de la Facultad, como es que se ha instalado el sistema de control de energía eléctrica que se

NotAS DE AUTOR

bgespezua@unap.edu.pe 
reemplazo del medidor antiguo, se hizo mejoras en el auditórium, cambiando las luminarias, el podio, fusibles y el sistema de drenaje, también se adquirió sillones móviles para cada uno de los docentes en cada aula, y se instaló computadoras en dichas aulas con su pupitre nuevo para cada docente y con uso de internet.

3.- En el año 2019, tuvimos el reconocimiento de docentes Honoris Causa, como fueron los Doctores Juan Antonio García Amado y Gerardo Hierro Molina, así mismo se empezó a implementar la Biblioteca virtual, dotando de computadoras para uso de los estudiantes, así como también se mejoró el Centro de Cómputo, se renovó el mobiliario de la sala de docentes. En dicho año se impulsó las ediciones de "Los Imprescindibles del Derecho", haciendo posible que se edite los dos primeros tomos de Hans Kelsen y de Gustavo Zarablesky, con estudios preliminares de colegas docentes, cuya serie debe continuar, además salió nuevamente la Revista de Derecho de la Facultad, como también los primeros libros de las mejores tesis de los estudiantes. Afines de dicho año se hizo reparaciones de una aula virtual que está ubicado en el cuarto piso para que funcione exclusivamente para actividades que requieran dicha tecnología, del mismo modo gestionamos dos equipos de pizarras virtuales que se instaló en la sala de docentes y en una aula de cuarto piso.

4.- En el año 2020, estuvo encargado como Decano por cinco meses el Dr. Sergio Serruto, quien salió por límite de edad y nuevamente asumí funciones, a partir de agosto de dicho año que nos encontramos con restricciones sanitarias por la pandemia del Covid-19 es que también se redujeron muchas actividades que debieran de haber proseguido. Todos entramos a una nueva era de virtualización para lo cual tuvimos capacitaciones para adaptarnos a las clases no presenciales y en el uso adecuado de plataformas virtuales. Así mismo, se conformó el Equipo de Bioseguridad de la Facultad, que permitió adquirir algunos insumos básicos para docentes y estudiantes. Es así como se repartió el kit de medicinas, alcohol, oxímetro y otros a todos los docentes para el cuidado de la salud, así mismo se adquirió fumigadores y la autoridad Universitario nos alcanzó un concentrador de oxígeno además que se instaló un equipo completo de limpieza a la entrada de la facultad.

Por otro lado debo de indicar, que hemos avanzado en el expediente del cumplimiento de los 34 estándares que se requiere para la reacreditación, también en lograr que las publicaciones, como son la revista de la Facultad y de la Unidad de posgrado prosigan y ahora tengan el reconocimiento de ser publicaciones indexadas en el nivel de Scielo, en forma virtual y de este modo podamos los docentes como otros invitados publicar en dichos órganos de difusión para contar con Docentes investigadores RENACYT en la Facultad.

5.- En lo que va en el presente año 2021, que se ha proseguido con el trabajo remoto, se ha culminado con el trabajo de la nueva currícula de estudios que ha sido aprobado en Consejo Universitario para que rija desde el presente año hasta el 2026. Además, debo indicar que hemos logrado con éxito desde el 2019, tener conforme a la Ley Universitaria la Unidad de Posgrado de Derecho, que comprende la Maestría y el Doctorado en Derecho y cuya oficina funciona en nuestra Facultad, así mismo hemos logrado convenios internacionales con la Universidad Católica Temuco de Chile y la UNAM de México, podemos decir que hemos incursionado en la internacionalización de la Facultad

En la parte final del presente informe debo agradecer a las siguientes personas: Sra. Liliana Romero, secretaria de la Decanatura, Dr. Juan Casazola, ex Director de Escuela, Presidente del Comité de Calidad, y Director de la Unidad de Posgrado de Derecho al Dr. Peter Manzaneda Director de Departamento, como lo fue la Dra. Marina Centeno a quien le agradezco su apoyo, Dr. Carlos Ramírez. Director actual de Escuela, a la Dra. Rosario Canal ex Secretaria Técnica, como lo fue y le agradesco la Dra. Diana Dueñas. Dr José Coya por su apoyo actual como Secretario Técnico, al Dr. Waldyr Alarcón, César Arapa a los docentes y personal administrativo que apoyaron en la gestión y a los jóvenes y promisorios abogados Michael Espinoza y Galymberti Ponce. Solo espero, que mi sucesor, el Dr. Manuel Quintanilla, continúe con la línea de consolidar el mejor servicio académico, administrativo de la Facultad y pueda seguir la ruta de asegurar la ansiada reacreditación. Exhortales a nuestros colegas que lo apoyemos, para que nuestra Facultad siga adelante, y por cierto siempre corrigiendo nuestras insuficiencias, que de no tenerlas mejorarían mucho la vida académica y administrativa de nuestra Facultad. 
Boris Gilmar Espezúa Salmón. Palabras de finalización de gestión del Decano Boris Espezúa Salmón

Muchas gracias.

Puno, 16 de julio del 2021.

BORIS ESPEZUA SALMON

Decano saliente. 